\title{
Multidrug Resistant Salmonella Species Isolated from Dam Water from Parts of Kaduna State, Nigeria
}

\author{
E.A. Aregbe ${ }^{1 *}$, O. S. Olonitola ${ }^{1}$, H.I. Inabo ${ }^{1}$, E.E. Ella ${ }^{1}$ and V.C. Ameso ${ }^{2}$ \\ ${ }^{1}$ Department of Microbiology, ${ }^{2}$ Department of Water Resources and Environmental \\ Management, Ahmadu Bello University, Zaria, Nigeria \\ *Corresponding author
}

\section{A B S T R A C T}

\section{Keywords}

Salmonella Species,

Multidrug

resistance, Galma

dam, Shika dam,

Kubanni dam

Article Info

Accepted:

06 July 2018

Available Online:

10 August 2018
Dam water from parts of Kaduna was investigated for the presence of multidrug resistant Salmonella spp. A total of four hundred and fifty water samples) were sampled from (Galma, Shika and Kubanni Dams. The samples were collected over a period of Ten months (October 2016- July 2017). The isolates were enriched in Selenite broth and streaked on Salmonella Shigella agar (SSA). From these samples, 27 isolates were confirmed to be Salmonella arizonae, 14 were Salmonella pullorum while 2 were Salmonella cholearesuis. They were all selected for antibiotic susceptibility testing using the Kirby-Bauer method. The isolates were tested for resistance to ten antibiotics. The highest resistance observed was to Ampicillin, Nalidixic acid and Amoxiclav 43(100\%) while all the isolates showed susceptibility to Imipenem and Ceftriaxone 43(100\%). Multidrug resistance were observed in $24(55.8 \%)$ of the isolates which showed resistance to six of the antibiotics while the least was 3(7.0\%) showing resistance to four antibiotics. The isolates that were resistant to the highest number of antibiotics were obtained from Shika dam and Galma water samples.. The isolation of antibiotic resistant bacteria in reservoir water is of public health concern due to the possibility of transferring multiple antibiotic resistances in the environment.

\section{Introduction}

Salmonella are facultative anaerobic, gram negative, small rods, motile (Bell and Kyriakides, 2002; Molbak, 2004). Salmonella species are classified and identified into serotypes according to the White-KauffmannLe Minor scheme; there are more than 2,500 Salmonella serotypes that have been described and reported (Wattiau et al., 2011). The genus Salmonella consists of two species S. enterica and $S$. bongori. Most of the serotypes pathogenic to humans and animals belong to S. enterica (Pui et al., 2011).

The Salmonellae are constantly found in environmental samples and in almost all types of aquatic environment, because they are excreted by humans, pets, farm animals, and wild life. Their presence in water, therefore, indicates faecal contamination. Municipal sewage effluents, pollution from agricultural 
products, storm water runoff from contaminated environments and direct deposit of faecal materials from wild animals and birds are the main sources of these pathogens in natural waters (Bhatta et al., 2007).

Salmonella causes four clinically distinguishable forms of infections in humans. These are gastroenteritis, enteric fever, bacteremia and other complications of non typhoidal salmonellosis as well as chronic carrier state in people of all ages. The transmission of Salmonella species takes place through the feacal-oral route, by means of contaminated food and water (Barry et al., 2012).Several antibiotics are used in the treatment of Salmonella serovars in both human and veterinary medicine, the overuse of these antibiotics has lead to the emergence of antibiotic drug resistance (Zhang et al., 2009).

The misuse of antimicrobial agents as chemotherapy in human and veterinary medicine or as growth promoter in food animals can potentially lead to widespread dissemination of antimicrobial resistance Salmonella and other pathogens via mobile genetic elements (Bouchrift et al., 2009). Recent findings showed the consequences of antibiotic resistant on human health (Abatcha et al., 2014). These consequences can be divided into two categories: first, the infections that may not have occurred and secondly, the high incidence of treatment failures and increase in the severity of disease (WHO, 2009). Moreover, resistance can spread from non-human sources to human by various routes such as animal, water and contaminated foods. However, contact with Salmonella carrier animal is the most important pathway in transmission of resistance to humans. Resistance to combinations of many classes of antimicrobial agents in Salmonella has led to the reemergence of multidrug resistance Salmonella
(MDR) strains that may pose a risk to humans (White et al., 2001; O'Brien, 2002). Many researches in the last two decades indicated the occurrence of MDR strains in different Salmonella serovars (Abatcha et al., 2014, Chen et al., 2004; Gebreyes and Thakur, 2005; Zhao et al., 2008). The emergence and persistence of antibiotic resistance in Salmonella species continue to pose serious risks to human health (Joseph et al., 2008). In Nigeria, morbidity associated with illnesses due to Salmonella continues to be on the increase and, in some cases, resulting in death. New concerns have been identified. Since the beginning of the 1990s, strains of Salmonella which are resistant to a range of antimicrobials, including first-choice agents for the treatment of humans, such as chloramphenicol and cotrimoxazole, and the third-generation cephalosporins, have emerged and are threatening to become a serious public health problem (Akinyemi et al., 2006, Hakanen et al., 2001).

\section{Materials and Methods}

\section{Study area}

The study was conducted in Kaduna State, Nigeria in three selected dams: The Galma dam, The Kubanni dam and The Shika dam.

\section{Collection of samples}

The water samples were collected in three different dams in Kaduna State, Nigeria which included the Galma dam, the Kubanni dam and the shika dam. A total of 450 water samples were taken from the three dams during a 10 month period. Using $2 \mathrm{~L}$ sterile plastic containers, raw water samples were collected from the reservoirs. The water samples were collected in batches and each batch of the samples were taken to the laboratory at $4^{0} \mathrm{C}$ in a cooler for analysis 
Enrichment and isolation of Salmonella spp from water samples

Approximately $10 \mathrm{ml}$ of each water sample was enriched in $10 \mathrm{ml}$ Selenite cystine broth (Difco) and incubated for $18-24$ hour at $37^{\circ} \mathrm{C}$. It was sub cultured onto Salmonella-Shigella agar (Oxoid) (SSA) and plates were incubated at $37^{0} \mathrm{C}$ for $48 \mathrm{~h}$ for isolation of salmonellae (Cheesebrough, 2006). Representative colonies from Salmonella-Shigellae agar (Oxoid) (SSA)plates showing growth presumptive for Salmonella was examined based on cultural and morphological characteristics that is transparent colonies with black centre and Gram stained (Cheesebrough, 2006).

\section{Biochemical characterization of isolates}

The following biochemical tests were done to identify Salmonella Species following Standard methods. Sugar fermentation in Triple Sugar Iron (TSI) agar, Hydrogen sulphide formation Test, Citrate utilization Test, Oxidase Test, Indole Test, Motility Test, Urease Test, Methyl red Test, VogesProskauer Test, Lysine decarboxylase Test (Mcall,1955) It was further Confirmed using a commercial identification Microgen test kits

Determination of antibiotic susceptibility profile of the isolates

The antibiotic susceptibility patterns of the isolates was determined using disk diffusion method of Kirby-Bauer on Mueller-Hilton agar according to CLSI guidelines for antimicrobial susceptibility testing (CLSI, 2017).

\section{Standardization of inoculum}

Pure culture of identified Salmonella isolates from an 18-hour plate culture was selected. Sterile wire loop was used to select 3 colonies of each Salmonella serotype and emulsified in
$5 \mathrm{ml}$ of sterile normal saline which was compared to $0.5 \mathrm{McFarland}$ standards. A sterile cotton swab was used to distribute the bacteria evenly over the entire surface of Mueller-Hinton agar. The inoculated plates were left at room temperature to absorb for 35 minutes. The antimicrobial disc concentration used were: Ampicillin,

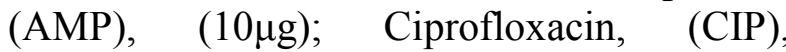
$(5 \mu \mathrm{g}) ; \quad$ Sulphamethoxazole-trimethprim (Cotrimoxazole), (SXT), $(25 \mu \mathrm{g}) ; \quad$ Nalidixic

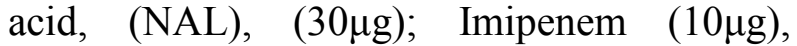

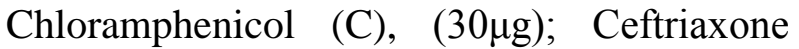

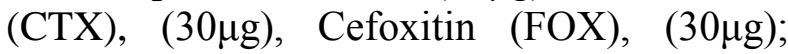

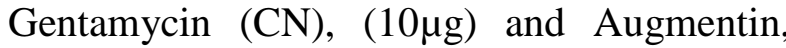
(AUG), $(30 \mu \mathrm{g})$. The antibiotic discs (Oxoid) were placed on the surface of the seeded Muller-Hinton plate and incubated at $37^{\circ} \mathrm{C}$ for 24 hours for growth. The diameter of the zone of clearance were measured to the nearest whole millimeter and interpreted on the basis of CLSI guidelines for antimicrobial susceptibility testing (CLSI, 2015). The multiple antibiotic resistance (MAR) index was calculated and interpreted according to Krumperman (1983).

\section{Data analysis}

The results were presented in the form of tables 1-4 while the association between the resistant rates of Salmonella isolates and also the antibiotic activities were also analysed using SPSS IBM (Version 20 for window) statistical package at $p<0.05$ level of significance

\section{Results and Discussion}

Distribution of organisms isolated from the water samples from the three dams

A total of 450 water samples were collected from three selected dams in parts of Kaduna State. S. arizonae was the most predominant accounting for $6.0 \%$, followed by S. pullorum $(3.1 \%)$ and S. choleraesuis $(0.4 \%)$. The Shika 
Dam (7.3\%) water samples were the most contaminated while Kubanni Dam (2.7\%) the least contaminated. There were significant differences among water samples which were positive for Salmonella $\operatorname{spp}(\mathrm{p} \leq 0.05)$;

The antimicrobial susceptibility pattern of the 43 Salmonella spp isolated from water samples using ten antibiotics. All the 43 isolates $(100 \%)$ were resistant to ampicillin, nalidixic acid and augmentin. They were also resistant to cefoxitin and cotrimoxazole with $95.3 \%$. Intermediate resistance occurred for chloramphenicol (60.5\%).The antibiotics effective against all the Salmonella isolates tested were ceftriaxone and imipenem (100\%), Gentamicin (93\%) and ciprofloxacin(74.4\%).

The antibiotic resistance profiles of $S$. arizonae, $S$. choleraesuis and $S$. pullorum from water samples to different antibiotics. High resistance to antibiotics were seen in most of the antibiotics used except for ceftriaxone and imipenem (100\%),
Gentamicin (93\%) and ciprofloxacin(74.4\%).

The antibacterial resistance patterns and the MAR index of selected bacterial species isolated from water samples to different antibiotics. Highest levels of multidrug resistant were observed in $24(55.8 \%)$ of the isolates which showed resistance to six of the antibiotics; $9(20.9 \%)$ of the isolates were resistant to five antibiotics; $7(16.3 \%)$ of the isolates were resistant to seven antibiotics; followed by $3(7.0 \%)$ that were resistant to four antibiotics. The highest resistance was seen with the 24(55.8\%) isolates showing resistance to six antibiotics.

The study revealed the presence of Salmonella in dam samples analyzed with an overall isolation rate of $9.5 \%$. This finding, in itself, is not surprising since higher isolation rates of Salmonella is reported to be present in water samples in Nigeria (Akinyemi et al., 2006, 2011; Oguntoke et al., 2009; Oluyege et al., 2009 and Jasini et al., 2016).

Table.1 Distribution of Salmonella spp from water samples from selected dams in Kaduna State

\begin{tabular}{|l|c|c|c|c|}
\hline Location (N=150) & $\begin{array}{c}\text { S. arizonae } \\
\text { No. isolated (\%) }\end{array}$ & $\begin{array}{c}\text { S. pullorum } \\
\text { No. isolated (\%) }\end{array}$ & $\begin{array}{c}\text { S. choleraesuis } \\
\text { No. isolated (\%) }\end{array}$ & p-value \\
\hline Shika dam (150) & $11(7.3)$ & $9(6.0)$ & $0(0.0)$ & 0.015 \\
\hline $\begin{array}{l}\text { Kubanni dam } \\
(\mathbf{1 5 0})\end{array}$ & $4(2.7)$ & $4(2.7)$ & $1(0.7)$ & \\
\hline Galma dam (150) & $12(8.0)$ & $1(0.7)$ & $1(0.7)$ & \\
\hline $\begin{array}{l}\text { Total Frequency } \\
\text { N=450 }\end{array}$ & $\mathbf{2 7 ( 6 . 0 )}$ & $\mathbf{1 4 ( 3 . 1 )}$ & $\mathbf{2 ( 0 . 4 )}$ & \\
\hline
\end{tabular}


Table.2 Antimicrobial susceptibility of Salmonella spp isolated from selected dams in Kaduna State

\begin{tabular}{|c|c|c|c|c|c|}
\hline \multirow[t]{2}{*}{$\mathbf{S} / \mathbf{N}$} & \multirow[t]{2}{*}{ Antibiotic } & \multirow{2}{*}{$\begin{array}{l}\text { Disc potency } \\
(\mu \mathrm{g})\end{array}$} & \multicolumn{3}{|c|}{ Susceptibility $(n=43)$} \\
\hline & & & $\begin{array}{l}\text { Sensitive } \\
\text { No }(\%)\end{array}$ & $\begin{array}{l}\text { Intermediate } \\
\text { No }(\%)\end{array}$ & $\begin{array}{l}\text { Resistant } \\
\text { No }(\%)\end{array}$ \\
\hline 1 & AMP & 10 & $0(0.0)$ & $0(0.0)$ & $43(100)$ \\
\hline 2 & NAL & 30 & $0(0.0)$ & $0(0.0)$ & $43(100)$ \\
\hline 3 & AMC & 30 & $0(0.0)$ & $0(0.0)$ & $43(100)$ \\
\hline 4 & FOX & 30 & $1(2.3)$ & $1(2.3)$ & $41(95.3)$ \\
\hline 5 & SXT & 25 & $2(4.7)$ & $0(0.0)$ & $41(95.3)$ \\
\hline 6 & $\mathrm{C}$ & 30 & $8(18.6)$ & $9(20.9)$ & $26(60.5)$ \\
\hline 7 & GEN & 10 & $40(93.0)$ & $0(0.0)$ & $3(7.0)$ \\
\hline 8 & IPM & 10 & $43(100)$ & $0(0.0)$ & $0(0.0)$ \\
\hline 9 & CIP & 5 & $32(74.4)$ & $1(2.3)$ & $10(23.3)$ \\
\hline 10 & CEF & 30 & $43(100)$ & $0(0.0)$ & $0(100)$ \\
\hline
\end{tabular}

KEY: $\mathrm{AMP}=$ ampicillin, IMP=Imipenem., $\mathrm{SXT}=$ cotrimoxazole, $\mathrm{NAL}=$ nalidixic acid, $\mathrm{AMC}=$ amoxicillin \&clavulanic acid, $\mathrm{CN}=$ gentamycin, $\mathrm{FOX}=$ cefoxitin, $\mathrm{C}=$ chloramphenicol, $\mathrm{CIP}=$ ciprofloxacin and $\mathrm{CEF}=\mathrm{Ceftriaxone}$

Table.3 Antibiotic resistance profile of S.arizonae, S.choleraesuis and S.pullorum isolated from water sampled from dams in Kaduna State

\begin{tabular}{|l|c|c|c|}
\hline \multicolumn{4}{|c|}{ Percentage of resistant isolates } \\
\hline & $\begin{array}{c}\text { S.arizonae } \\
(\mathbf{n}=\mathbf{2 7})\end{array}$ & $\begin{array}{c}\text { S.pullorum } \\
(\mathbf{n = 1 4})\end{array}$ & $\begin{array}{c}\text { S.cholearesuis } \\
(\mathbf{n = 2})\end{array}$ \\
\hline Antibiotics & & & \\
\hline AMP & 100 & 100 & 100 \\
\hline AMC & 100 & 100 & 100 \\
\hline SXT & 92.6 & 100 & 100 \\
\hline NAL & 100 & 100 & 100 \\
\hline FOX & 92.6 & 100 & 100 \\
\hline GEN & 7.4 & 7.1 & 100 \\
\hline IPM & 0.0 & 0.0 & 0.0 \\
\hline CIP & 29.6 & 14.3 & 0.0 \\
\hline C & 55.5 & 71.4 & 50.0 \\
\hline CEF & 0.0 & 0.0 & 0.0 \\
\hline
\end{tabular}

$\mathrm{N}=$ Total Number(\%) of Salmonella isolates resistant to antibiotics $\mathrm{n}=$ Number of isolates that are resistant.

KEY:AMP = ampicillin, IMP=Imipenem., SXT = cotrimoxazole, NAL =nalidixic acid, $\mathrm{AMC}=$ amoxicillin \&clavulanic acid, $\mathrm{CN}=$ gentamycin, $\mathrm{FOX}=$ cefoxitin, $\mathrm{C}=$ chloramphenicol, $\mathrm{CEF}=$ ceftriaxone, $\mathrm{CIP}=$ ciprofloxacin 
Table.4 Antibacterial resistance patterns of Salmonella species isolated from water samples to 10 different antibiotics

\begin{tabular}{|c|c|l|l|}
\hline $\begin{array}{c}\text { Number of } \\
\text { Antibiotics }\end{array}$ & $\begin{array}{c}\text { Number of resistant } \\
\text { isolates }(\mathbf{\%})\end{array}$ & Resistant pattern & MARI \\
\hline $\mathbf{4}$ & $3(7.0)$ & AMP-NAL-AMC-FOX & 0.4 \\
\hline $\mathbf{5}$ & $9(20.9)$ & AMP-SXT-NAL-AMC & 0.5 \\
\hline $\mathbf{6}$ & AMP-SXT-NAL-AMC-FOX & 0.6 \\
\hline $\mathbf{7}$ & AMP-NAL-AMC-FOX-C & \\
\hline & AMP-SXT-NAL-AMC-FOX-C & \\
\hline & & AMP-SXT-NAL-AMC-CIP-FOX & \\
\hline
\end{tabular}

KEY:AMP = ampicillin, $\mathrm{SXT}=$ cotrimoxazole, $\mathrm{NAL}=$ nalidixic acid, $\mathrm{AMC}=$ amoxicillin \&clavulanic acid, $\mathrm{CN}=$ Gentamicin, FOX=cefotaxime, $\mathrm{C}=$ chloramphenicol, $\mathrm{CIP}=$ ciprofloxacin

Moreover, previous studies reported that Salmonella may survive and remain virulent for long periods in the environment,, they may undergo a viable but nonculturable stage as a survival strategy when they encounter environmental stresses and cause infection (Martinez et al., 2005) The 9.5\% isolation rate of Salmonella obtained is however, lower than the $16 \%$ isolation rate by Adzitey et al., (2016) from Dam water used for drinking in Tamale, Ghana and $13.3 \%$ by Oluyege et al., (2009) in Nigeria.

The distribution of Salmonella species showed that a total of Forty three Salmonella isolates were obtained from the water samples collected from these selected dams and the most common specie isolated in this study were $S$. arizonae, $S$. pullorum and $S$. choleraesuis. S. arizonae and S. pullorum, were isolated from all the three dam sites while $S$. choleraesuis were isolated from only Kubanni and Galma dam. These result showed that their presence in water, therefore, indicates faecal contamination, Sewage effluents, agricultural run-off and direct deposit of faecal materials from wild animals, reptiles and birds which are the major sources of the contamination in aquatic environments. The results agreed with the findings of (Arii et al., 2002; Chen et al., 2004, Parry et al., 2002, Martinez et al., 2005) who had faecal contamination in there samples.

The importance of susceptibility testing cannot be over emphasized. It provides guidance to selective use of drug for therapy and information on the spectrum of an antimicrobial agent. Therefore, it is of great importance to monitor antibiotic resistance among pathogenic bacteria isolates from water samples to detect emerging resistant 
pathogens and antibiotic resistance trends (Heuer et al., 2011). From the results obtained in this study, The antimicrobial susceptibility pattern of the 43 Salmonella spp isolated from the water samples using ten antibiotics revealed that Ceftriaxone and Imipenem was the most susceptible with 43(100\%) followed by Gentamycin and Ciprofloxacin with $93 \%$ and $74.4 \%$ respectively.

43 isolates were $100 \%$ resistant to Ampicillin, Nalidixic acid, and Amoxiclav followed by Cotrimoxazole and Cefoxitin with $95.3 \%$ while Chloramphenicol had $60.5 \%$ in order of decreasing resistance. The findings compares with Effa et al., (2011), Tesfaw et al., (2013), Poonia et al., (2014), Jasini et al., (2016) who stated that third-generation cephalosporin such as ceftriaxone and fluoroquinolones are the drugs of choice for first line of treatment. The origin of resistance in water samples can be traced to the faecal constituent of the raw water from the dams. The high rate of multidrug resistance by Salmonella isolates correlates with the works of Adley et al, (2011) and Oluyege et al., (2009), which reported that Salmonella exhibit multidrug resistant patterns to more than four antibiotics. This result could be due to the overuse of antibiotics in animals as growth promoter. The mass treatment and long-term administration of antimicrobial growth promoters to animals may lead to the emergence of multidrug-resistant strains of enteric bacteria, including Salmonella spp. highest resistance seen in Ampicillin, Nalidixic acid and Amoxiclav could also be due to the usage of these drugs both in human medicine. This has resulted in the increase in the development of increasing number of resistance strains to so many antibiotics through the horizontal gene transfer by mobile genetic elements. The high resistance could also be due to the use of fake or expired drugs, abuse and misuse of the drugs among the general populace. In the developing world it is a serious problem particularly when the drugs are purchased in local drug stores without appropriate prescription thereby taken at low dosages and at times results in incomplete dosages only to alleviate symptoms. Most of the time the guidelines regarding selection of the drug prescription are not communicated to individuals that purchase this drugs thereby leading to self limiting infections especially when they are not bacterial infections but viral infections prescribed when not needed. Many countries don't have effective surveillance systems thereby leading to high morbidity and mortality rates, longer period of infectivity, increased cost and prolong hospital stay (Abdullahi et al., 2013; Collingnon, 2003). The situation in the developing countries like Nigeria is however different, where antimicrobial agents are readily available to people in local drug stores without prescription (Kwaga and Adesiyun, 1984). The isolates being susceptible to Ceftriaxone, Imipenem, and Gentamycin could be due to cost effective and parenteral route for administration (Crump et al., 2008). Antibiotic susceptibility patterns vary regionally and geographically and have been reported to change rapidly over time (Martinez et al., 2005). The multiple antibiotics resistant patterns of Salmonella spp from water samples in this study is greater than 0.2 which implies that the strains of such Salmonella spp originated from an environment where several antibiotics are in use (Ehinmidu, 2003; Poonia et al., 2014).

In conclusion, the study revealed the presence of Salmonella spp in dam samples analyzed with an overall isolation rate of $9.5 \%$. All the Salmonella spp isolates were resistant to at least one of the antibiotics used in the study, indicating multiple resistance due to possible transfer of resistance genes. All the 43 isolates $(100 \%)$ were resistant to ampicillin, nalidixic acid and Augmentin. The antibiotics 
effective against all the Salmonella isolates tested were ceftriaxone and imipenem (100\%), Gentamicin (93\%) and ciprofloxacin (74.4\%).

\section{Recommendation}

Based on the findings it is therefore recommended that attention should be focussed by both the public and government on putting in place antibiotic resistance surveillance programs in the country and infections due to multidrug resistant salmonella can be eliminated not by massive use of antibiotics but by improvement in the conditions of animal husbandry and reduction in the opportunities for the initiation and spread of the diseases.

\section{References}

Abatcha, M.G., Zakaria, Z., Kaur, D.G. and Thong, K. L (2014). Review Article: A trends of Salmonella and antibiotic resistance. ALFST, 7:9-21.

Abdullahi, I., Humuani, K. A. and Musa, D., , (2013), The challenges of domestic wastewater management in Nigeria: A case study of Minna, central Nigeria. IJDS 2(2), 1169-1182.

Adzitey, F, Ashiagbor, C.K.N, Abu, H. (2016). Prevalence and susceptibility of Salmonella spp. from water sources in Tamale, Ghana. IJOH, 2:24-28

Adley, C., Dillon, C., Morris, C.P., Delappe, N., Cormican, M (2011). Prevalence of Salmonella in pig ear pet treats. FRI. 44:193-197.

Akinyemi, K.O., Oyefolu, A.O.B., Salu O.B., Adewale., O.A., and Fasure., A.K. 2006 Bacterial pathogens associated with tap and well waters in Lagos. Nigeria. ECAJS, 11(1), 110-117.

Arii, J., Tanabe, Y., Miyake, M., Mukai, T., Matsuzaki, M., Niinomi, N., Watanabe, H., Yokota, Y., Kohno, Y. and Noda, M. 2002. Clinical and pathologic characteristics of non typhoidal Salmonella encephalopathy. N58(11):1641-1645.

Barry P.A., Jones, M.A., Smith, A.L. and Wigley, P. 2012. The long view: Salmonella - the last forty years. Avian Pathology, 41: 413-420.Morocco. JIDC, 3(1): 35-40.

Bell, C., and A. Kyriakides. 2002. Salmonella: a practical approach to the organism and its control in foods. Blackwell Science Limited, Ames, Iowa, USA

Bhatta, D.R., Bangtrakulnonth, A., Tishyyadhigama, P., Saroj, S.D 2007 Serotyping, PCR, Phage- typing and antibiotic sensitivity testing of Salmonella serovar isolated from urban drinking water supply systems of Nepal. Letters in Applied Microbiology, 44: 588-594

Bouchrif,, B., Paglietti, B., Murgia, M., Piana, A.F., Cohen, N., Ennaji, M.M., and Timinouni, M. 2009. Prevalence and antibiotic-resistance of Salmonella isolated from food in Morocco. JIDC, 3(1): 35-40.

Chen, S., Zhao, S., White, D.G. and Schroeder, 2004. Characterization of multiple- antimicrobial- resistant Salmonella serovars isolated from retail meats AEM 70:1-7.

Cheesbrough, M. 2006. District Laboratory Practice in Tropical Countries. Cambridge University Press, UK pp. 136.

CLSI. (2015). Performance standards for antimicrobial susceptibility testing; Fifteenth informational supplement, CLSI Wayne, Pa. M100- S15, 25(1).

Collingnon, P. 2003 A review-the use of anibiotics in food production animalsdoes this cause problems in human health. Manipulating pig production IX. Proceedings of the Ninth 
Biennial Conference of the Australasian Pig Science Association (Inc.) (APSA), Femantle, Western Australia. p73-80

Crump J.A., Kretsinger, K., Gay, K., Hoekstra, R.M., Vugia, D.J., Hurd, S., Segler, S.D., Megginson, M., Luedeman, L.J. and Shiferaw, B. 2008. Clinical response and outcome of infection with Salmonella enterica serotype Typhi with decreased susceptibility to fluoroquinolones: a United States foodnet multicenter retrospective cohort study. AAC 52:1278-1284

Effa, E.E., Lassi, Z.S, Critchley JA, Garner P, Sinclair D, Olliaro PL, Bhutta ZA. Bhutta, Zulfiqar A, 2011. Fluoroquinolones for treating typhoid and paratyphoid fever (enteric fever). Cochrane Database System; 10.

Ehinmidu J.O, 2003. Antibiotics susceptibility patterns of urine bacterial isolates in Zaria, Nigeria. TJPRvol. (2). 223-228,

Gebreyes, W.A., and Thakur, S. 2005. Multidrug-resistant Salmonella enterica serovars Muenchen from pigs and humans and potential interserovar transfer of antimicrobial resistance. AAI, 49: 503-511.

Hakanen A, Kotilainen P, Huovinen P 2001. Reduced fluoroquino-lone susceptibility in Salmonella enterica serotypes in travelers returning from Southeast Asia. EID 7: 9961003.

Joseph, S.W., Sapkota, P., Cullen, D., Wagner, M., Hulet, J., Hayes, S., Sahu, S., Gadwal, L.E. and Carr, B.H 2008. Reduced resistance to antibiotics among Salmonella sp. Recovered from U.S. Organic Poultry Farms. American Society for Microbiology conference 2008 proceeding, $1752 \mathrm{~N}$ Street, N.W. Washington, DC,

Krumperman, P.H. (1983). Multiple antibiotic indexing Escherichia coli to identifying risk sources of faecal contamination of foods. AEM, 46:165-170

Kwaga, J. and Adesiyun, A.. (1984) Antibiogram of Staphylococcus aureus isolates from some ready to eat products. Journal of Food Prot.,4 7(11): 865-867

McCall, A. J. (1955). An Introduction to Medical Laboratory Technology.JCP, $8(2), 183$.

Mølbak, K. (2004). Spread of resistant bacteria and resistance genes from animals to humans - the public health consequences. JVM. B, Infectious Diseases and Veterinary Public Health, 51, 364-369

O'Brien, T.F. (2002). Emergence, spread, and environmental effect of antimicrobial resistance: how use of an antimicrobial anywhere can increase resistance to any antimicrobial anywhere else. CID 34(3):78-S84.

Oguntoke, O., Aboderin, O. J. and Bankole, A.M. 2009. Association of waterborne diseases morbidity pattern and water quality in parts of Ibadan City, Nigeria. TJHR 11(4): 189-195.

Oluyege, J.O., Dada, A.C and Odeyemi, A.T. 2009.Incidence of multiple antibiotic resistant Gram- negative bacteria isolated from surface and ground water sources in south western region of Nigeria. WST 59(10):1929-1936

Parry, C.M., Hien, T.T., Dougan, G., White, N.J. and Farrar, J.J. (2002). Typhoid fever. NEJM 347:1770-1782.

Poonia, (2014). Antibiotic Susceptibility Profile of Bacteria Isolated from Natural Sources of Water from Rural Areas of East Sikkim. IJCM Official Publication of Indian Association of Preventive \& Social Medicine, 39(3), 156-160. http://doi.org/10.4103/09700218.137152 
Pui, C. F., Wong, W. C., Chai, L. C., Nillian, E., Ghazali, F. M., Cheah, Y. K. Nakaguchi, Y., Nishibuchi, M. and Son, R.. 2011. Simultaneous detection of Salmonella spp., Salmonella typhi and Salmonella typhimurium in sliced fruits using multiplex PCR.FC 2: 337 342.

Tesfaw, L.B. Taye, S. Alemu, H. Alemayehu, Z. Sisay, and H. Negussle. 2013 Prevalence and antimicrobial resistance profile of Salmonella isolates from dairy products in Addis Ababa, Ethiopia. AJ7(43), 5046-5050

Wattiau, P., Boland, C. and Bertrand, S. 2011. Methodologies for Salmonella enterica subsp. enterica subtyping: gold standards and alternatives. AEM77:7877-7885.

\section{How to cite this article:}

Aregbe, E.A., O. S. Olonitola, H.I. Inabo, E.E. Ella and Ameso, V.C. 2018. Multidrug Resistant Salmonella Species Isolated from Dam Water from Parts of Kaduna State, Nigeria. Int.J.Curr.Microbiol.App.Sci. 7(08): 823-832. doi: https://doi.org/10.20546/ijcmas.2018.708.092 